\title{
A. I. Conejo, Colores, Barcelona, La Garúa Libros, 2007, 72 pp.
}

El poema "Esencia”, que cierra Colores (2007), el último libro de Ana Isabel Conejo, premio Màrius Sampere de poesía, resume lo "esencial" de su poemario en dos versos: "Las cosas tienen el significado / que el uso les otorga". El diccionario académico define la esencia como lo permanente e invariable de la sustancia de una cosa, lo cual contradice la variabilidad que la poeta atribuye a los colores, pero no lo permanente, porque "así es siempre"; siempre tienen las cosas "el significado / que el uso les otorga". También los colores, porque como la poeta enuncia, los colores variaron y varían de significación (de simbolismo) según los pueblos, la cultura y las costumbres: "un color es sólo / el largo aprendizaje de su nombre / a través de la lengua y la costumbre, / un largo entrenamiento del ojo / sometido al lenguaje".

"El ojo sometido al lenguaje": el primer poema plantea el viejo asunto de la relación entre las palabras y los conceptos. Se ha dicho que si no disponemos de la palabra, no disponemos del concepto; vemos los colores que nombramos. "El griego antiguo no dispone de un término específico que designe el azul", lo que quiere decir que los griegos no veían el mundo como nosotros lo vemos. Hay algo más: su percepción del color consonaba con su mundo de valores y su modo de vivir; de ahí que percibieran con nitidez los colores de la batalla. ¿No veían los griegos el azul ni el color del cielo? Lúcidamente la poeta nos dice que veían un color variable, el que cada día y cada hora tenía el cielo en cada lugar, matizado por olores, sabores, sentimientos y cantos de cada momento, "un color indecible que nosotros no vemos": es decir, nosotros tampoco tenemos nombre para ese color indecible: el ojo sometido al lenguaje. Tan ciegos eran los griegos para el azul como nosotros para ese color indecible y variable.

Ana Isabel Conejo nos introduce así, como ya he indicado, en el problema lingüístico, psicológico y poético de la relación de palabras y conceptos; al igual que en el segundo poema, "Loros" nos plantea un enigma de la ciencia: ¿cómo es posible que exista un ser como el loro, con un plumaje de fondo rojo tan intenso que la poeta lo llama "imposiblemente rojo"? ¿Por qué, si tal color es reclamo peligroso para los depredadores de todo tipo? Con este poema nos introduce en otro enigma, que ya no es el del lenguaje y los conceptos, sino el de la naturaleza. No es la poesía de Ana Isabel Conejo una poesía enigmática, en la que el artificio oculte el sentido (enigmática es la poesía de Celan, Valente o Gamoneda, por ejemplo) sino que plantea racionalmente el asombro ante los enigmas del mundo en un poema como "Loros".

El poemario nos irá conduciendo hacia temas como la distancia entre lo que parece y lo que es, entre lo que vemos y la realidad, entre ésta y el ojo que la mira (el conocido engaño de los ojos que poetizaron o teatralizaron nuestros poetas barrocos), la sabia naturaleza en la que nada parece gratuito, en la que todo tiene una razón de ser, trátese del color, del fulgor momentáneo, de la transición de colores en el cielo o de las alas leves de la mariposa cuando se pliegan; de la distancia entre los colores de la mediocridad -los ocres de la tierra humilde- y los azules ideales de los sueños... 
De modo general, los poemas se inician con una constatación histórica o filológica o del arte de la tintorería: “En Rouen, a principios del siglo XVI, la guerra / entre los tintoreros del rojo y del azul / forzó la intervención de las autoridades" ("Tintoreros"); "El fin no siempre justifica el medio, / y algunas prácticas (las mezclas / de amarillo y azul), no deben aceptarse / como procedimientos de tintura" ("Receta medieval para teñir de verde"), etc. Y a partir de tales aseveraciones va haciéndose el poema con curiosas observaciones sobre el oficio de tintar, por ejemplo, o sobre las cualidades del color. Estamos en el ámbito de la poesía y las cualidades y calidades del color no son las que apreciaría un tintorero o un pintor, pongamos por caso, sino las que siente la poeta, que traza definiciones metafóricas tal vez inapropiadas fuera del ámbito lírico.

El punto de partida exige otro de llegada. Y si aquel es aparentemente objetivo, empírico, el desarrollo del poema va matizando la idea, de forma que lo que era aceptado como cierto va arbitrándose como creencia más que como verdad, acaso como prejuicio, opinión común que la poeta puede ir derruyendo, como en ese hermoso poema titulado "Ajedrez", en el que el juego de "blancas contra negras" ("desangelado contraste de miserias / entre las luces y las sombras"), que simboliza una determinada visión del mundo, la poeta nos lo hace ver como símbolo pobre y no universal, por cuanto en otras culturas jugaron negras contra rojas o rojas frente a blancas. Así percibimos que nuestra manera de ver y pensar tiene grietas por las que es posible entrar para deconstruirla, en este caso desde el pensamiento poético.

En otras ocasiones no se trata de matizar o de deconstruir nuestra visión del mundo, sino de proyectar la idea objetiva hacia ámbitos del espíritu. Así ocurre en el poema "Mordiente", en el que se parte de la idea de que algunos pigmentos necesitan "alguna sustancia intermediaria" para impregnar bien las telas. Y el asunto recibe esta proyección sobre la facultad humana de la memoria: "Lo mismo le sucede a la memoria; / que sus rojos intensos / no agarran bien la trama del futuro / si no media algo más / (miedo, ternura, o cierta / implicación del alma) / que adhiera a nuestra historia su violencia". En estas proyecciones hacia el ámbito interior (psicológico, sentimental o de otro tipo) es donde la intervención del yo como personaje del poema parece más cercana. Este yo se manifiesta explícitamente en piezas como "Efecto óptico", que poetiza el barroco engaño de los ojos: "No hay pájaros azules, / mi Amor....".

"El blanco y su silencio", "el azul y su mística”, "el rojo y su violencia" ("Tricolor"): los colores no son neutros. No están sólo en las cosas; nacen también de dentro, del recuerdo, de las vivencias y las amarguras del corazón. El color evoca y convoca. Y en esa evocación de lo vivido y sentido, convocado al presente por la palabra, cada color se va tiñendo de diferentes tonalidades cercanas a la melancolía, como sucede en los poemas titulados "Verde" -en el que se evocan "aquellos días en que nos bañábamos en playas ácidas de esperanza y tristeza"-, "Azul" -en el que la poeta afirma saber ahora "todo cuanto se alza / desde la voluntad hasta el deseo"-, "Rojo" -el color de la violencia para la poeta, que evoca otro tiempo en el que llevaba "carmín de 
tristeza en los labios": "En aquel tiempo yo tenía / la edad incalculable de mi miedo..."-, "Amarillo" -el color de la decadencia, de "las páginas más viejas / de la memoria", y que a la poeta le evoca a ella misma, "yo atrapada en mi propio corazón", como Narciso en el espejo de las aguas- y "Negro" -que evoca viejas fotografías familiares ambientadas en la tristeza, como el propio yo en "la ternura desolada de mis dieciocho años", con todos los engaños, rencores y olvidos con que aquellos años se rememoran-.

La idea de que los colores no son neutros y que no están tanto en las cosas como en el ojo que las mira está hermosamente expresado en el poema "Cartas a Théo", donde los pensamientos que la poeta pone en boca de Van Gogh, además de expresar el mundo pictórico del hoy célebre pintor neerlandés, reflejan la idea que recorre el poemario sobre la interpretación variable de los colores, que residen, más que en el mundo exterior, en el ojo que lo percibe: “No está en mí la verdad; yo sólo busco / el contraste secreto que no captan los ojos. / No está en mí la verdad. No está en las cosas, / sino en la audaz acción de la mirada.

Poesía del color es esta poesía, no colorista. Poesía del color que, casi de manera inevitable, había de acercar la poesía a la pintura en poemas como "El matrimonio Arnolfini", alusivo al célebre cuadro de Van Eick, "La paleta de Velázquez" o "Turner". La poesía sobre lienzos pictóricos parte de una ausencia: la del cuadro. La écfrasis intenta paliar la ausencia "poniendo ante los ojos" el objeto que no vemos por medio de la descripción. La écfrasis quiere evidenciar, evocar, despertar en el lector la presencia de la obra artística ausente. De ahí la importancia de un título como "El matrimonio Arnolfini", índice pragmático primero del hecho de que nos encontramos ante un poema sobre un lienzo concreto. Pero sucede que la écfrasis no deja de ser algo ilusorio, pues el poema es representación (poética) de lo que ya era representación (pictórica); de ahí que el poema ecfrástico, es decir, alusivo a un lienzo que describe poéticamente, exprese doblemente el fracaso de cualquier representación: la imposibilidad de apoderarse del objeto, por lo que se ha dicho que es esencialmente un poema elegíaco, pues expresa una pérdida, la pérdida del objeto. Lo ausente es inicialmente el cuadro, pero más allá, y de modo más hondo y trágico, la realidad.

La poeta -como es frecuente en los poemas de este tipo- raramente permanece en la mera descripción, sino que deriva fácilmente hacia el encomio o hacia la interpretación personal. "El matrimonio Arnolfini" se inicia con una frase descriptiva: "Giovanni Arnolfini, mercader de Lucca, lleva puesto un sombrero de castor negro. Las medias, los zapatos y el vestido son de ese mismo tono...", pero se desliza de inmediato hacia el posible significado del color: "porque negra ha de ser la lealtad entre los hombres que intercambian bienes...". Y lo mismo sucede al tratar de la figura femenina del cuadro: "Giovanna Cenami lleva un vestido azul y una amplia capa verde adornada con orlas de piel blanca"; es la parte ecfrástica, a la que sigue la búsqueda del significado simbólico: “El azul significa lealtad, alimento e infancia...", y "combinado con verde (color del matrimonio), evoca vida que aflora de lo húmedo", pero "Giovanna nunca tuvo hijos", por lo que la poeta proyecta lo 
concreto hacia un valor universal: "No hay piedra / filosofal en el color. Ni símbolo / que pueda utilizarse como llave / para forzar las arcas del futuro...". La misma tónica sigue "La plata de Velázquez": a la descripción ecfrástica ("Los reyes, los bufones, todos visten de negro"), sigue la interpretación ("Será porque se sienten culpables de existencia"), con proyección personal final, pues los colores desvaídos, entre el rojo y el negro, "guardan la memoria de todo lo que es bello / e inútil a la vez en nuestro corazón".

En Colores, el ritmo parece acomodarse al discurrir del pensamiento, de forma que en muchos poemas parece que nos hallamos más cerca de la prosa que del verso; "Loros", por ejemplo, avanza entre argumentaciones, dudas y posibilidades, con frases parentéticas e incidentales que nos lleva a pensar en el lenguaje ensayístico, por ejemplo. Véase, asimismo, el comienzo de "Arco iris": "Tres colores ostenta según Aristóteles, dos según San Gregorio [...]. Innumerables son, por el contrario, los colores del arco iris en opinión de Ovidio y de Virgilio. Lo atestiguan así ciertos mosaicos del siglo II en Pérgamo...". Los bloques rítmicos, el talante narrativo, el aprovechamiento de datos de la ciencia antigua en determinados poemas, puede hacernos recordar la estructura de los poemas de Gamoneda a partir de Lápidas o la conversión en poesía de la antigua materia médica en Libro de los venenos (la mención de Dioscórides en el poema "Índigo" es otro indicio); pero no hay la fascinación gamonediana por el lenguaje médico de la Antigüedad, convertido en poesía cuando ha perdido sus valores de utilidad y uso, ni el sentido de "fármaco" que el libro de Gamoneda tiene, en el doble sentido de triaca y veneno. Por otro lado, en poemas de A. I. Conejo como los citados o como "Camaleón" o "Quipus" podemos preguntarnos -al igual que se ha hecho con las prosas gamonedianas- ante qué género nos encontramos, pues si en dichos poemas no podemos hablar de versos o versículos, tal vez tampoco podamos hablar de poemas en prosa en su concepción habitual. En todo caso, poesía, superando la división genérica. Desde mi apreciación, las prosas poéticas de Ana Isabel Conejo tienden a aprovechar recursos rítmicos endecasilábicos, es decir, se construyen como una sucesión de heptasílabos y endecasílabos principalmente, pero no de forma regular, pues es propio del ritmo ser tejido de expectativas, satisfacciones, desilusiones y sorpresas provocadas por la sucesión de sílabas, según explicó en su día I. A. Richards. En cualquier caso, la poeta, dueña de su lenguaje, ha sido capaz de infundir poesía a distintos registros del lenguaje en un libro mayor, construido sobre proyecto previo, unitario, por lo tanto, en tonalidad y asunto, que ofrece perspectivas nuevas y de vario tipo en la obra poética hasta ahora publicada.

José Enrique Martínez 